\title{
SIMULAÇÃO DE HABITAÇÃO SOCIAL EM UM VAZIO URBANO CENTRAL
}

\author{
Verônica de Freitas ${ }^{1}$
}

\author{
Cristina Maria Perissinotto Baron ${ }^{2}$
}

\author{
Marcos Faccioli Gabriel ${ }^{3}$
}

\section{RESUMO}

Este trabalho apresenta uma simulação de implantação de habitação de interesse social em um vazio urbano na área central da cidade de Presidente Prudente - SP. O motivo dessa simulação é ocupar os lotes urbanos subutilizados nas áreas centrais, pois estes locais geralmente são degradados e este tipo de moradia apresenta várias vantagens, por exemplo economia nos custos, pois estas áreas centrais apresentam infraestrutura e transporte consolidado, redução na expansão horizontal da área urbana, auxílio no déficit habitacional. Assim, analisou-se os vazios urbanos centrais e finalizou-se com uma simulação de ocupação em um vazio urbano específico.

PALAVRAS-CHAVE: Habitação Social. Vazio Urbano. Déficit Habitacional.

\section{SIMULATE FOR SOCIAL HOUSING IN A VACANT CENTRAL URBAN}

\footnotetext{
${ }^{1}$ Mestre em Engenharia Civil. Docente no Instituto Federal de Educação Ciência e Tecnologia de São Paulo - Campus de Presidente Epitácio. Rua José Ramos Junior, 27-50, Jardim Tropical, CEP 19470-000, Presidente Epitácio-SP. (18) 3281-9595. E-mail: veronica@ifsp.edu.br । veronicaifsp@gmail.com.

2 Doutora em Arquitetura e Urbanismo. Docente na Universidade Estadual Paulista Júlio de Mesquita Filho - Campus de Presidente Prudente. Rua Roberto Simonsen, 305, Centro Educacional, CEP 19060-900, Presidente Prudente-SP. (18) 3229-5388. E-mail: crisbaron@fct.unesp.br.

${ }^{3}$ Mestre em Arquitetura e Urbanismo. Docente na Universidade Estadual Paulista Júlio de Mesquita Filho - Campus de Presidente Prudente. Rua Roberto Simonsen, 305, Centro Educacional, CEP 19060-900, Presidente Prudente-SP. (18) 3229-5388.
} 
Revista Nacional de

Gerenciamento de Cidades

\begin{abstract}
This paper presents a simulate for deployment of housing of social interest in an urban void in the central area of the city of Presidente Prudente - SP. The reason for this simulate is to occupy the urban lots underutilized in the central areas, as these sites are usually degraded and this villa has several advantages, such cost savings, as these central areas have consolidated infrastructure and transport, reduced horizontal expansion urban area and aid the deficit housing. Thus, we analyzed the central urban voids and ended up with a simulate for a specific occupation in an empty city.
\end{abstract}

KEY-WORDS: Social Housing. Vacant Urban. Deficit Housing.

\title{
SIMULACIÓN DE VIVIENDA SOCIAL EN UN VACÍO CENTRAL URBANA
}

\begin{abstract}
RESUMEN
Este artículo presenta una simulación del despliegue de vivienda social en un vacío urbano en la zona central de la ciudad de Presidente Prudente - SP. La razón de esta simulación ocupe subutilizada suelo urbano en las áreas del centro, ya que estos sitios suelen ser degradado y esta villa tiene varias ventajas, por ejemplo, el ahorro de costes, ya que estas áreas centrales han consolidado la infraestructura y el transporte, la reducción de la expansión horizontal área urbana, la asistencia en el déficit habitación. Por lo tanto, se analizaron los vacíos urbanos centrales y terminamos con una ocupación de simulación en una ciudad específica vacía.
\end{abstract}

PALABRAS CLAVE: Habitación Social. Urbano Vacante. Habitación Déficit.

\section{INTRODUÇÃO}

O presente trabalho propõe um projeto de habitações de interesse social em um vazio urbano na área central de Presidente Prudente - SP. Este empreendimento visa contribuir para amenizar problemas urbanos, ou seja, os vazios urbanos e o déficit habitacional.

No caso do vazio urbano, entenda-se neste trabalho, lote ocioso, que se valoriza com a expansão da cidade, por meio da especulação imobiliária sem realizar nenhum benefício à sociedade. Assim, a simulação é aproveitar de forma racional o uso destes lotes vazios urbanos.

Geralmente estes lotes encontram-se em áreas degradadas que necessitam de requalificação, portanto, esta simulação tem o intuito de traçar uma ação pontual 
Revista Nacional de

Gerenciamento de Cidades

para iniciar a melhoria do seu entorno, por meio da implantação de um conjunto habitacional de interesse social, que beneficie a população de baixa renda, por ser a que mais necessita de moradia, conforme indica o déficit habitacional brasileiro.

A simulação desse trabalho baseia-se em desenvolver-se unidades habitacionais com tipologias diferenciadas, evitando ambiências monótonas e que garantam habitabilidade ${ }^{4}$. Pretende-se, dessa forma, aproveitar a infraestrutura existente na área central e ao mesmo tempo relacionar-se com o entorno, preocupar-se com o meio físico e construído, de maneira a inserir a população de baixo poder aquisitivo na área central, que comumente está segregada na periferia da urbe.

Para esta simulação optou-se em basear no Programa de Arrendamento Residencial (PAR), que atende os municípios com mais de 100.000 habitantes para famílias com renda de até $\mathrm{R} \$ 1.800,00$. Desconsiderou o Programa Minha Casa Minha Vida (MCMV), lançado em 2009, pela Secretaria Nacional de Habitação do Ministério das Cidades, pois este atende outras faixas de renda, sendo três faixas na área urbana, faixa 1 renda mensal: até $R \$ 1.600$, faixa 2 até $R \$ 3.275$ e faixa 3 até $\mathrm{R} \$ 5$ mil. E o foco desta simulação foi atender as famílias com renda até três salários mínimos, a mais dependente da produção habitacional realizada pelo Estado.

\section{OBJETIVO}

Apresentar uma simulação de uma habitação de interesse social, com tipologias diferenciadas e acessíveis.

\footnotetext{
${ }^{4}$ Habitabilidade, segundo a Cartilha Produção Social do Habitat é um termo que não se limita a unidade habitacional em sua construção, abrange outras faces coletivas e privadas, físicas, psicológicas, sociais e culturais. É um conceito complexo, que envolve muitos aspectos que afetam a qualidade da moradia, como a qualidade da casa em termos de material de construção, área construída, divisões internas e instalações, a segurança da posse da terra, a infraestrutura de abastecimento de água, esgoto, drenagem, sistema viário, forma do bairro e disponibilidade de equipamentos urbanos e serviços públicos, transporte, segurança, áreas de lazer e convivência comunitária, entre outros.
} 
Revista Nacional de

Gerenciamento de Cidades

Promover o alcance social da população de baixa renda ao instalá-los em moradias na área central da cidade, em geral segregadas espacialmente, por meio da inadequada produção do espaço urbano.

Enfocar na habitação de interesse social para as pessoas com renda até três salários mínimos, com benefícios que contribuam na habitabilidade.

Incentivar que os lotes não edificáveis exerçam a função social da propriedade.

\section{METODOLOGIA}

A priori realizou-se uma revisão literária dos principais tópicos abordados e posteriormente foi necessário ter conhecimento da cidade de estudo de caso, Presidente Prudente - SP. Assim, realizou-se levantamento dos acessos à cidade, definição e localização no mapa da área central, seus índices urbanísticos, uso e ocupação do solo e os principais vazios urbanos existentes na área central.

Em seguida, definiu-se o vazio urbano central para a simulação de intervenção com o projeto de uma habitação social, considerando-se na escolha a facilidade de acesso, localização do lote em relação ao entorno, para o público alvo); a vocação do local (uso e ocupação do lote), a topografia (declividade do lote e principais vistas) e dimensões do lote (diante da simulação de habitação de interesse social).

$\mathrm{Na}$ sequência levantou-se informações da área de estudo, como o levantamento planialtimétrico, estudo da malha viária, do gabarito, do entorno sobre equipamentos comunitários, mobiliário urbano, uso e ocupação do solo e do mercado imobiliário.

Assim, definiu-se o plano de necessidades e o trabalho conclui-se com a simulação de um projeto de interesse social em uma área central na cidade de Presidente Prudente - SP e de uma maquete eletrônica. 
Revista Nacional de

Gerenciamento de Cidades

\section{MÉTODO DE ANÁLISE}

O método de análise inicial foi apresentar de maneira clara alguns conceitos e aspectos primordiais para compreender os pontos centrais na elaboração da simulação da habitação de interesse social. Por conseguinte, utilizou-se os aspectos da NBR 6492 (ABNT,1994), no sentido de auxiliar o processo projetual.

\subsection{Vazios Urbanos}

Segundo Marques (2005), a produção de moradias nas cidades inclui ao menos quatro formas. A primeira são as edificações construídas pelos próprios moradores, distante da lógica do mercado capitalista. A segunda são os pequenos construtores que edificam por encomenda ou contratação. A terceira é a produção pública, por meio do Estado, direcionada principalmente para as camadas de baixo poder aquisitivo. E por último os incorporadores, que edificam para obter sobre lucros fundiários, que têm um papel importante na produção das cidades, pois é responsável pela segregação social.

Assim, os incorporadores são o polo mais avançado do ponto de vista capitalista, pois condicionam quais são os espaços da cidade que se pode ou não ocupar. Eles direcionam as áreas que o Estado poderá atuar, determinando a estrutura da cidade.

Como aborda Rodrigues (1994), os incorporadores, ao decidirem a expansão da malha urbana, acabam escolhendo alguns espaços vazios para sofrerem especulação imobiliária. Estas áreas se apropriam de uma valorização conquistada pelo coletivo, e geralmente, não trazem nenhum benefício à população.

De acordo com Rodrigues (1994, p. 22) "[...] os proprietários que deixam a terra vazia, ociosa, sem nenhum uso, apropriam-se de uma renda produzida socialmente.

A retenção de terras vazias para aguardar sua valorização é uma das principais causas do não acesso da população à moradia. Perto de $50 \%$ das áreas 
Revista Nacional de

Gerenciamento de Cidades

urbanas são mantidas vazias com este objetivo. Essa valorização provém dos investimentos públicos enquanto os ganhos são apropriados privadamente pelos proprietários de terras, RODRIGUES (1994, p.62).

BONKUKI, (1993) também trabalha com a afirmação de Rodrigues (1994) e define "[...] "vazios urbanos - glebas e terrenos localizados na área urbanizada mantidos ociosos pelos seus proprietários como reserva de valor em prejuízo de toda a cidade[...]".

Os "vazios urbanos" são vistos como um problema nas cidades atuais, pois servem de abrigo a marginais, depósito tecnogênico (entulho) e contribuem para a proliferação de vetores causadores de doenças, principalmente em períodos de chuva.

Diante dessas afirmações, diretrizes pontuais de ocupação desses lotes ociosos podem vir a ser o início de uma solução para as áreas centrais, pelo fato de promover uma nova ocupação do uso do solo e iniciar pontualmente a melhora destes ambientes degradados.

\subsection{Habitação de Interesse Social}

Uma das formas de ocupação dos lotes subutilizados é a habitação de interesse social, que atua amenizando a demanda habitacional e ainda pode propor a requalificação de um vazio urbano na área central com entorno degradado, de forma a promover a inclusão social.

Esta iniciativa de integração já acontece nos grandes centros de cidades como: São Paulo - SP, Recife - PE, São Luís - MA, com propostas de revitalização de cortiços, edifícios abandonados e a reurbanização de favelas, ou seja, aproveitase o patrimônio cultural dos ambientes centrais, como aborda Campos (1999).

Estas estratégias buscam condições básicas de habitabilidade, qualidade de ambiência urbana local, aumento da oferta de cômodos de aluguel no centro, 
Revista Nacional de

Gerenciamento de Cidades

desarticulação do quadro de exploração de sublocações, garantia de manutenção, conservação dos imóveis e promoção da ressocialização dos moradores.

As propostas de revitalização nos centros históricos são interessantes, entretanto, têm expulsado a população de menor poder aquisitivo para a periferia, já que estas áreas se valorizam.

Para isto, estudou-se o modo de pensar a habitação de interesse social, na época do Instituto de Aposentadoria e Pensões (IAP), realidade existente no Brasil, que apesar de não suprir a demanda, realizou conjuntos habitacionais interessantes, com arquitetura reconhecida internacionalmente, na qual existia o anseio pela qualidade de vida do trabalhador, de forma a the conceder dignidade e habitabilidade.

Os arquitetos pensavam não apenas na habitação mínima para o morador, mas em áreas complementares que garantissem a habitabilidade, como: áreas de lazer, espaços coletivos e preocupação com o entorno (vias e meio ambiente).

\subsection{Déficit Habitacional}

Atualmente, a necessidade de moradia é um problema nacional. De acordo com a Fundação João Pinheiro (FJP), estima-se que o déficit habitacional no ano de 2010 era da ordem 6.950 milhões de habitações, sendo que $85 \%$ estão em áreas urbanas.

O conceito de déficit habitacional segundo a FJP divide-se em duas partes: a primeira é déficit por reposição do estoque de moradias, relacionado à precariedade as construções, incluindo os domicílios rústicos e uma parcela de domicílios existentes depreciados.

A segunda é o déficit por incremento de estoque, ou seja, domicílios improvisados, coabitação e ônus excessivo com aluguel (renda familiar até três salários mínimos, residentes em casa ou apartamento que despendem mais de $30 \%$ da renda com aluguel). 
Revista Nacional de

Gerenciamento de Cidades

A coabitação familiar é o componente mais expressivo do déficit habitacional, correspondendo a $60 \%$, o ônus excessivo com aluguel de $29 \%$ e a habitação precária de $11 \%$, totalizando juntas $100 \%$, segundo dados da FJP (2005).

A Fundação João Pinheiro também apresenta estimativas revisadas da distribuição percentual do déficit habitacional urbano por faixas de renda no Brasil. $82,5 \%$ está na faixa de até três salários mínimos; $9,4 \%$ de três a cinco; $5,8 \%$ de cinco a dez e 2,3\% mais de dez salários mínimos.

A partir destes dados, verifica-se a existência de uma concentração do déficit habitacional em determinado estrato de renda, ou seja, a população com até três salários mínimos mensais. Portanto, conclui-se que a classe de menor poder aquisitivo é a maior depende do Estado. Todavia, os programas habitacionais do poder público tende a abranger as famílias com renda familiar mensal de cinco a oito salários mínimos, segundo a FJP.

Este breve esclarecimento do déficit habitacional nacional afirma a relevância de se trabalhar nesta temática, principalmente com a simulação pertinente de ocupar um vazio urbano na área central com habitação de interesse social.

\subsection{Estudo de Caso}

A cidade de Presidente Prudente encontra-se na região sudeste do Brasil e apresenta 207.610 habitantes, segundo a estimativa populacional de 2010 do Instituto Brasileiro de Geografia e Estatística (IBGE). É considerada, portanto, uma cidade de porte médio.

A rodovia do estado de São Paulo, Raposo Tavares é um dos principais acessos a cidade de Presidente Prudente - SP, por meio das principais vias da cidade Avenida Brasil, Avenida Manoel Goulart, Avenida Washington Luís e a Avenida Coronel José Soares Marcondes.

Para iniciar a simulação da habitação de interesse social na área central fez se necessário levantar alguns vazios urbanos centrais, sendo que o primeiro 


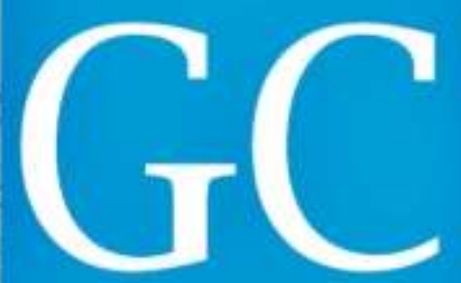

Revista Nacional de

Gerenciamento de Cidades

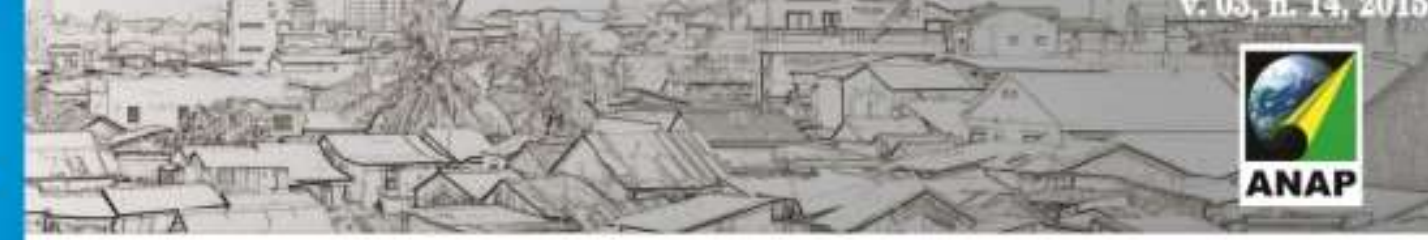

apresenta uma área de 4394,03 $\mathrm{m}^{2}$ (A1), o segundo $2048,31 \mathrm{~m}^{2}$ (A2) e o terceiro $6815,12 \mathrm{~m}^{2}(\mathrm{~A} 3)$.

A área que mais se adequa ao objetivo do trabalho é a área de 4394,03 $\mathrm{m}^{2}$ (A1). O principal motivo refere-se à localização e à facilidade de acesso, conforme o público alvo, pois tem-se a proximidade do terminal urbano e do quadrilátero comercial. Entretanto, considerou-se também a degradação e a função social da propriedade.

O fator degradação é essencial para a simulação de requalificação quando o vazio urbano está inserido em uma zona de prostituição, tráfico de drogas e não cumpre a função social da propriedade. Assim, o não cumprimento contribui para a desapropriação da área, que é de propriedade privada. Se o lote fosse público, terse-ia a redução no custo da implantação do projeto, pois não seria necessária a compra. É importante ressaltar que a questão custo em habitação social é um item de grande importância. Portanto, requalificar (mudar o uso) neste lote será uma ação pontual para contribuir não só com a transformação do entorno, mas fazer com que o lote exerça a função social da propriedade.

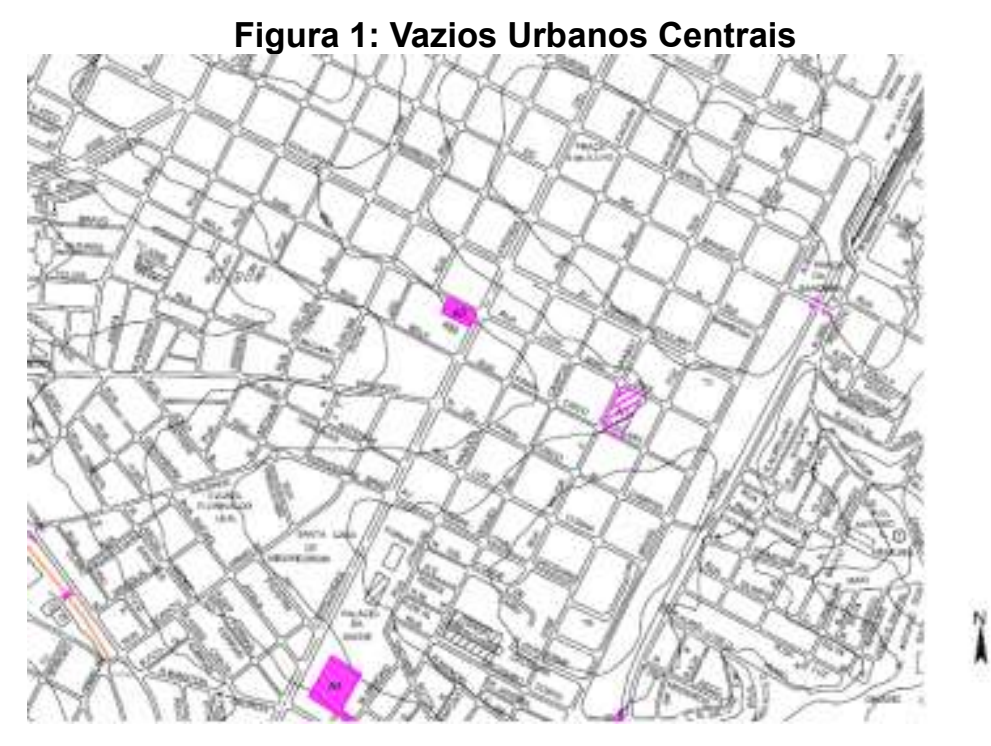

Fonte: Prefeitura Municipal de Presidente Prudente, adaptado, 2014. 
Revista Nacional de

Gerenciamento de Cidades

ainda, que a soma dos usos voltados ao comércio e serviço supera o número de lotes destinados a residências.

Outro estudo realizado foi em relação às instituições existentes próximas à área de intervenção, percebendo-se uma quantidade de instituições consideráveis, com forte presença de escolas, serviços e saúde. Somente a área de lazer apresentou-se de forma deficitária. As duas únicas praças presentes nesta área de estudo encontram-se distantes da área de intervenção. Para finalizar o diagnóstico, verificou-se a viabilidade da simulação do empreendimento, com a análise do mercado imobiliário local.

É fundamental saber o valor do lote da área de intervenção deste trabalho, pois diz respeito à desapropriação por ser uma propriedade particular. Esse lote, por estar em uma área central, comumente apresenta valores mais elevados do município, visto que toda a infraestrutura se encontra consolidada.

Para estimar o valor do lote escolhido, foram utilizadas duas fontes de dados, primeiramente os dados coletados a partir das guias de Imposto sobre a Transmissão de Bens e Imóveis (ITBI) do ano 2000, dados Melazzo (2008). Seguidos pelos anúncios imobiliários de compra e venda do jornal O Imparcial da cidade de Presidente Prudente - SP, no ano de 2006.

A primeira fonte de dados, o ITBI, obteve-se um valor médio do lote de $\mathrm{R} \$ 74,64$. E na segunda fonte, jornal O Imparcial, obteve-se o valor médio do metro quadrado construído de $\mathrm{R} \$ 428,37$. Ambos os valores foram utilizados como pontos de partida para a estimativa de preço do lote em questão e para definir o partido arquitetônico das edificações a serem implantadas.

Para obter o preço médio do vazio urbano central estudado, multiplicou-se sua área $\left(4394.03 \mathrm{~m}^{2}\right)$ por $\mathrm{R} \$ 74,64 \mathrm{~m}^{2}$, obtendo-se o valor médio total do lote de $\mathrm{R} \$$ $327.970,40$, este será o valor médio a ser pago na desapropriação. Em relação ao valor médio do metro quadrado construído nesta região da cidade (lote + edificação) é de $\mathrm{R} \$ 428,37$, que, multiplicado pela área do lote $\left(4394.03 \mathrm{~m}^{2}\right)$, resulta no valor médio da área construída $(\mathrm{R} \$ 1.882 .248,66)$. 
Revista Nacional de

Gerenciamento de Cidades

Este resultado é fundamental para chegar-se ao número de unidades mínimas que viabilizem o empreendimento. Para isto, dividiu o valor final médio da área construída ( $R \$ 1.882 .248,66)$, pelo valor médio da unidade que se pretende construir (R\$30.000,00), baseado no programa PAR da CEF. Consideram-se agregados neste valor, o lote, a construção e as taxas de projeto.

Conclui-se que devem ser edificadas 62 unidades no mínimo, para viabilizar e racionalizar o uso do lote. O número mínimo de unidades em relação à área de intervenção $\left(4394.03 \mathrm{~m}^{2}\right)$ inviabiliza a construção de casas isoladas no lote, sendo inevitável a sua verticalização. Portanto, como foram simuladas 68 unidades habitacionais, têm-se que cada residência teve um custo estimado de $R \$ 27.680,13$, ou seja, custo inferior ao programa PAR da CEF de R\$30.000,00.

\section{RESULTADOS E CONCLUSÃO}

\subsection{Simulação Intervenção}

Este trabalho não é apenas uma residência, mas um conjunto delas, logo haverá outras atividades a desenvolver-se no local. Neste sentido, a análise do mercado imobiliário do entorno foi de grande importância para definir o programa de necessidades e o dimensionamento. Após este estudo houve uma mudança na proposta de uso do solo, que passou de residencial para uso misto, com a simulação de galerias, para fins comerciais e/ou serviço.

Assim, o programa será composto no geral por: habitação, ampla área de lazer, centro de apoio ao condomínio, guarita e galerias. As tipologias das habitações serão compostas por: sala, dormitórios, cozinha, área de serviço e banheiros.

De acordo com a lei complementar $n^{\circ} 128 / 2003$, de Presidente Prudente - SP, art. 25 , capítulo $V$, todo edifício ou conjunto residencial com mais de 12 unidades deverá ter uma área de recreação equipada, obedecendo uma quota mínima de 6 $\mathrm{m}^{2}$. Como simulou-se 68 unidades habitacionais, a área mínima de lazer deverá ser 
Revista Nacional de

Gerenciamento de Cidades

de 408,00 $\mathrm{m}^{2}$ que deverão ser protegidos de ruas, locais de acessos e estacionamento. A simulação do projeto propôs uma área recreativa entre os blocos de habitação de $1125.89 \mathrm{~m}^{2}$.

O levantamento do entorno resultou em um diagnóstico do uso do solo e do gabarito, que alterou a proposta inicial de uso residencial para uso misto. A mudança implicou na presença de galerias voltadas para a fachada principal do lote, ou seja, para a Rua Major Felício Tarabai, para favorecer o comércio e/ou serviço.

Para entender a malha viária do entorno do lote, na Figura 1, a cor laranja representa as vias locais e na cor vermelha, a via arterial. Esta via arterial, denominada Avenida Brasil, é uma das quatro principais ligações de acesso à cidade, demonstrando que o lote se encontra completamente inserido na malha urbana.

Para início do desenvolvimento do projeto, tirou-se partido de algumas análises. A primeira foi descartar o uso dos elevadores, por encarecer o empreendimento, exigir manutenção constante, que implicaria em uma demanda de recursos e pela análise do gabarito do entorno da área de intervenção.

A simulação de intervenção nesse vazio urbano é uma habitação de interesse social, se fosse adotado o uso de elevadores, ou seja, mais de quatro pavimentos, seria interessante trabalhar com oito pavimentos, o dobro, de maneira a aproveitar a instalação desses. No entanto, essa ação resultaria em uma edificação de gabarito elevado e iria destoar do entorno da área de intervenção.

As construções nessa área mais comuns são as de gabaritos térreos, com variação de até cinco pavimentos e apenas um prédio de dezesseis pavimentos, entrando em conflito com a paisagem do entorno.

A princípio, a habitação na parte térrea agora passou a desenvolver-se sobre uma laje, fazendo com que o projeto ganhe uma área que poderá contribuir para a solução de uma área de lazer e para atender o número mínimo de vagas de estacionamento, previsto em lei municipal ( $70 \%$ das unidades). 
Revista Nacional de

Gerenciamento de Cidades

O conjunto de habitações recebeu o nome de Residencial Amanhecer, sendo um projeto de uso misto composto conforme o programa de necessidades por: habitação, área recreativa, centro de apoio ao condomínio, guarita, estacionamento e galerias comerciais.

A habitação é constituída por dois blocos lineares, cada um de quatro andares, ambos sobre uma laje. O bloco próximo a divisa do lote foi denominado Sol, devido estar com a orientação para leste, e o outro bloco denominado Lua, pela orientação oposta. As habitações apresentam cinco tipologias diferentes para atender as diversas estruturas familiares existentes, conforme mostra a Figura 2.

Figura 2: Disposição das tipologias no $1^{\circ}$ pavimento.

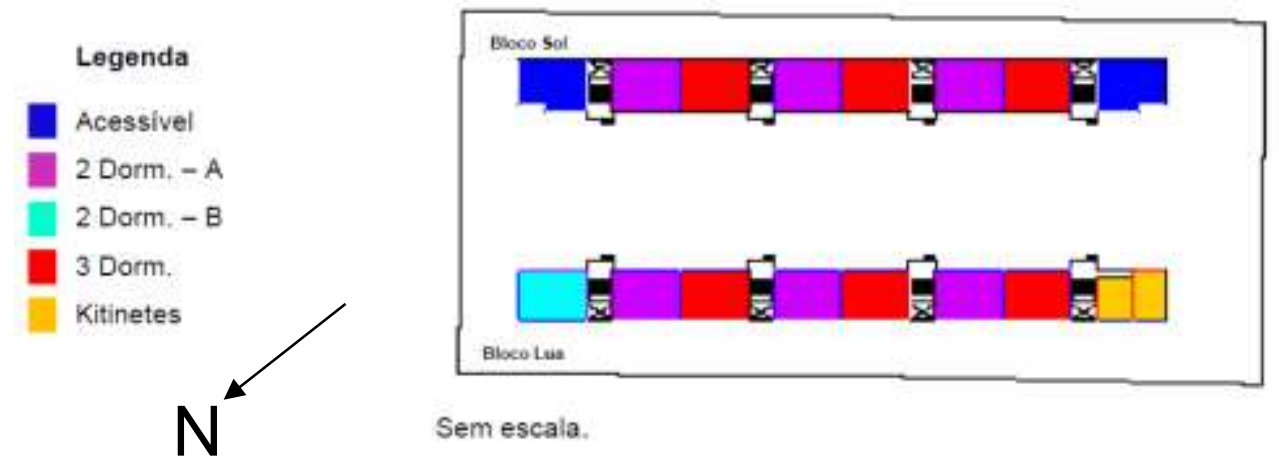

A seguir a Figura 3 ilustra os pavimentos tipo $\left(2^{\circ}, 3^{\circ}\right.$ e $\left.4^{\circ}\right)$, sendo que estes não têm as unidades acessíveis. Na cor roxa são as tipologias de 2 dormitórios - $A$, com seis unidades, como no $1^{\circ}$ pavimento, distribuídas três para cada bloco. Na cor azul claro a tipologia de 2 dormitórios - $B$, com três unidades, sendo duas unidades no bloco Sol, que substituem as acessíveis do $1^{\circ}$ pavimento e uma unidade no bloco Lua. A cor vermelha são as tipologias de 3 dormitórios, com seis unidades, também igual ao $1^{\circ}$ pavimento, distribuídas três para cada bloco e por fim, na cor laranja as tipologias kitinetes, com duas unidades, uma diferente da outra, assim como no $1^{\circ}$ pavimento, estão apenas no bloco Lua.

As áreas das unidades são aproximadamente de $60,00 \mathrm{~m}^{2}$, conforme menciona o código sanitário do Estado de São Paulo sobre habitação de interesse 


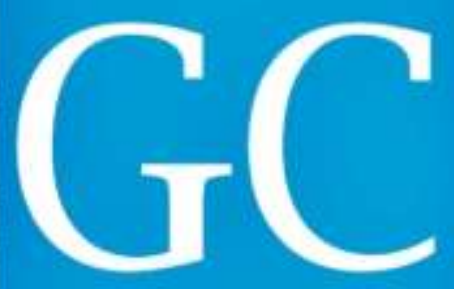

Revista Nacional de

Gerenciamento de Cidades

social. Buscou-se trabalhar próximo ao limite, pelo fato da habitação multifamiliar dificultar a flexibilidade de ampliação. As tipologias kitinetes apresentam a área reduzida, aproximadamente metade, ou seja, $30 \mathrm{~m}^{2}$.

Figura 3: Disposição das tipologias no $1^{\circ}$ pavimento.
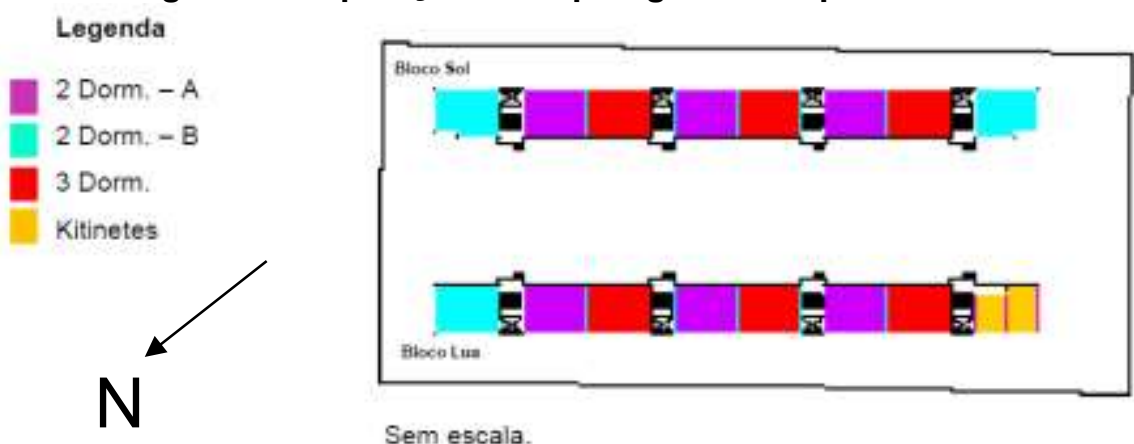

Na Figura 4 tem-se um corte esquemático da simulação do condomínio na qual se desenvolve os espaços diversificados na área de lazer para atender as diferentes faixas etárias, com nichos em cotas de níveis diferentes até acessar a laje de acesso aos apartamentos.

Figura 4: Corte Esquemático.

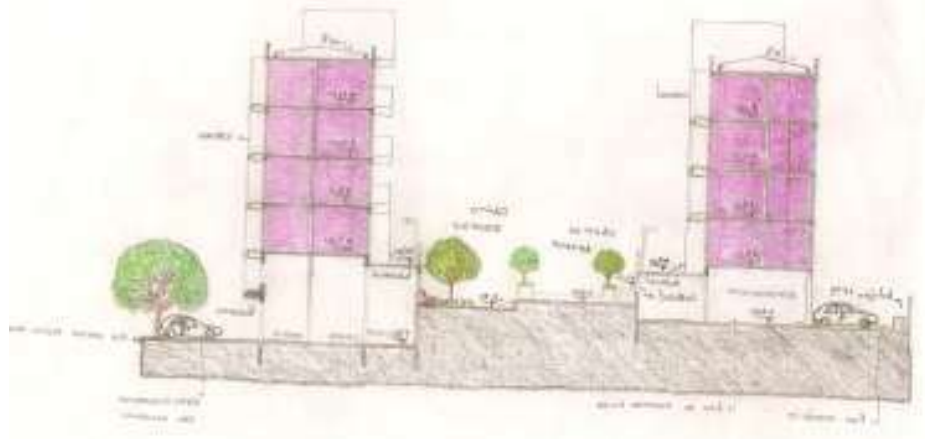

As lajes, as quais as habitações se desenvolvem, ao se unirem formam praças convidativas à convivência comunitária. Em relação ao estacionamento para os moradores do Residencial Amanhecer, este abrange veículos, motos e bicicletas. 


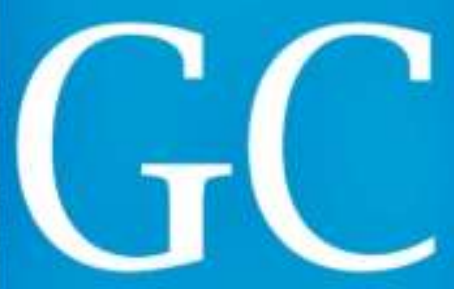

Revista Nacional de

Gerenciamento de Cidades

O estacionamento é do tipo privativo (de utilização exclusiva da população permanente da edificação multifamiliar), como aborda a lei complementar 152/2008, no art. 108. Esta mesma lei traz outras recomendações, no art. 109, onde menciona que os edifícios privativos com mais de 100 vagas deverão reservar $1 \%$ das vagas aos deficientes físicos.

Como são 68 unidades, reservou-se uma vaga acessível, em um total de 52 vagas. O número mínimo seria de 48 vagas, que equivale a $70 \%$ das unidades. Entretanto, ao reservar 52 vagas, o residencial atingiu o corresponde a $76 \%$ das vagas destinadas aos moradores.

Figura 5: Vista geral do Residencial Amanhecer

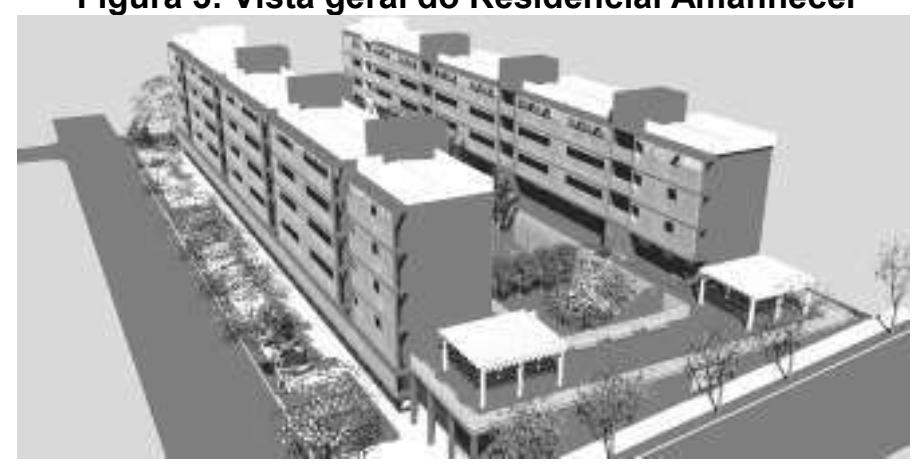

\section{CONSIDERAÇÕES FINAIS}

A habitação é um dos direitos fundamentais da população e o seu déficit é um problema nacional, que atinge o estrato da população mais carente. $O$ déficit habitacional brasileiro vem aumentando a cada ano como analisado na Fundação João Pinheiro e no município da cidade de Presidente Prudente - SP.

Assim, a temática da habitação social em um vazio urbano central torna-se pertinente diante da realidade, o que torna viável o objetivo de ocupar um lote subutilizado que não cumpre a função social da propriedade. 
Revista Nacional de

Gerenciamento de Cidades

O Residencial Amanhecer é uma ação pontual para iniciar a requalificação de uma área degradada. A sua implantação seria algo inédito na cidade de Presidente Prudente - SP.

A sua instalação, além de atender 68 famílias da população de baixa renda, tem a finalidade de inserir este público alvo em um local estratégico devido à proximidade do terminal urbano e do quadrilátero central, com equipamentos públicos consolidados, aproximando-os do trabalho, o que implica em redução dos custos com transporte.

A questão de inserir esta população na área central implicou na verticalização da habitação, para viabilizar o empreendimento, pois o lote está inserido em uma das áreas mais cara do município. Portanto, o fato de ser um residencial, gera as taxas condominiais, por isso tirou-se partido da forte presença do comércio/serviço do entorno e surgiu a proposta das galerias, para reduzir os custos dos moradores.

Ao desenvolver as tipologias, outra preocupação foi em optar pela diversidade de habitação para atender as diversas famílias, complementada por uma ampla área recreativa, uma forma de estender a residência para o exterior, de maneira a valorizar as relações sociais entre os moradores.

Em suma, a simulação do projeto arquitetônico desenvolvido a todo instante tentou atender a população com renda familiar até três salários mínimos, evitar custos condominiais com a criação das galerias, uso misto do solo, habitabilidade com ampla área de lazer, sempre na busca de satisfazer o morador em residir com qualidade e dignidade inserido espacialmente na malha urbana.

\section{REFERÊNCIAS}

AMORIM, Margarete Cristiane de Costa Trindade. O clima Urbano de Presidente Prudente - SP. Presidente Prudente. 2000. 332f. Tese (Doutorado em Geografia Física) - Faculdade, Letras e Ciências Humanas, Universidade de São Paulo, São Paulo, 2000.

ASSOCIAÇÃO BRASILEIRA DE NORMAS TÉCNICAS. NBR 6492: Representação de projetos de arquitetura - elaboração. Rio de Janeiro, 1994. 


\section{Revista Nacional de}

Gerenciamento de Cidades

BONDUKI, Nabil Georges. Arquitetura \& Habitação Social em São Paulo 1989-1992. Edição e Textos Nabil Bonduki, Universidade de São Paulo, Escola de Engenharia de São Carlos,

Departamento de Arquitetura e Planejamento, 1993.

BONDUKI, Nabil Georges. Origens da habitação social no Brasil: arquitetura moderna, lei do inquilinato e difusa da casa própria. 4. ed. São Paulo: Estação Liberdade, 2004. 344 p.: il.

BRASIL, Constituição Federal - Coletânea de Legislação de Direito Ambiental. São Paulo: Revista dos Tribunais, 2004.

CAMPOS, Heleniza Ávila. Permanências e mudanças no quadro de requalificação sócioespacial da área central do Recife (PE): estudo sobre territorialidades urbanas em dois setores "revitalizados". 1999. Rio de Janeiro. Tese (Doutorado- Centro de Ciências Matemáticas e da Natureza) - Universidade Federal do Rio de Janeiro. (Programa de Pós - Graduação emGeografia), Rio de Janeiro,1999.

CHALHOUB, Sidney. Cidade Febril: Cortiços e epidemias na Corte imperial. São Paulo: Companhia das Letras, 1996.

GRUPO DE ARQUITETURA E PLANEJAMENTO (GAP). Habitação Popular Inventário da Ação Governamental, FINEP/Projeto, Rio de Janeiro, 1985.

HABITAT PARA A HUMANIDADE BRASIL. Produção Social do Habitat. Recife, 2007. Disponível em: <http://www.habitatbrasil.org.br> Acesso em: 23 mar. 2015.

MARQUES, Eduardo; TORRES, Haroldo. Segregação, Pobreza e Desigualdades Sociais. São Paulo: SENAC, 1. ed., 2005. 329 p.

MELAZZO, Everaldo Santos. Guias de Imposto sobre a Transmissão de Bens e Imóveis (ITBI). 2000. Arquivo pessoal.

MUNFORD, Lewis. A cidade na História. São Paulo: Martins Fontes, 1983, p.567 a 611.

RODRIGUES, Arlete Moysés. Moradia nas cidades brasileiras. Revisão Rosa M. C. Cardoso e Cândida M. V. Pereira. 5. ed. São Paulo: Contexto, 1994.

SPÓSITO, Eliseu Savério. Produção e apropriação da renda fundiária urbana em Presidente Prudente. Tese (Doutorado em Geografia) - Faculdade, Letras e Ciências Humanas, Universidade de São Paulo, São Paulo, 1990. 